\title{
Aquatic Adaptation and Swimming Mode Inferred from Skeletal Proportions in the Miocene Desmostylian Desmostylus
}

\author{
Philip D. Gingerich ${ }^{1,2}$
}

\begin{abstract}
Desmostylians are enigmatic, extinct, semiaquatic marine mammals that inhabited coastlines of the northern Pacific Rim during the late Oligocene through middle Miocene. Principal components analysis (PCA) of trunk and limb proportions provides a rational multivariate context for separating living semiaquatic mammals on three orthogonal axes: a size axis (PC-I), a degree of aquatic adaptation axis (PC-II), and a forelimb- versus hind-limb-dominated locomotion axis (PC-III). The necessary skeletal measurements are available for Desmostylus hesperus but not for other desmostylians. Among species similar in size to Desmostylus in the study set, the one most similarly proportioned is the polar bear. Projection of Desmostylus on PC-II shows it to have been more aquatic than a polar bear (indicated by its relatively short ilium and femur, combined with relatively long metapodals and phalanges). Projection of Desmostylus on PC-III suggests that its aquatic locomotion was even more forelimb-dominated than that of a bear (indicated by its relatively long metacarpal III and corresponding proximal phalanx, combined with a relatively short metatarsal III and corresponding proximal phalanx). Desmostylians were different from all living semiaquatic mammals, and desmostylians are properly classified in their own extinct order, but their skeletal proportions suggest that bears provide an appropriate baseline for imagining what desmostylians were like in life.
\end{abstract}

KEY WORDS: Swimming style, Locomotion, Semiaquatic mammals, Desmostylus, Desmostylia.

\section{INTRODUCTION}

Desmostylians are an unusual group of extinct semiaquatic mammals known from upper Oligocene (Chattian) through middle Miocene (Serravallian) marine strata of the northern Pacific Rim, ranging from Japan to Mexico, and represented by teeth, skulls, and skeletons (Fig. 1). They were large mammals with body weights on the order of a ton or more (Inuzuka, 1996).

The first desmostylian fossil was described from California by Othniel Charles Marsh (1888). This was a partial upper molar with three conjoined pillars or columns of enamel,

\footnotetext{
${ }^{1}$ Department of Geological Sciences and Museum of Paleontology, The University of Michigan, Ann Arbor, Michigan 48109-1079, USA.

${ }^{2}$ To whom correspondence should be addressed at Department of Geological Sciences and Museum of Paleontology, The University of Michigan, Ann Arbor, Michigan 48109-1079, USA. E-mail: gingeric@ umich.edu
} 

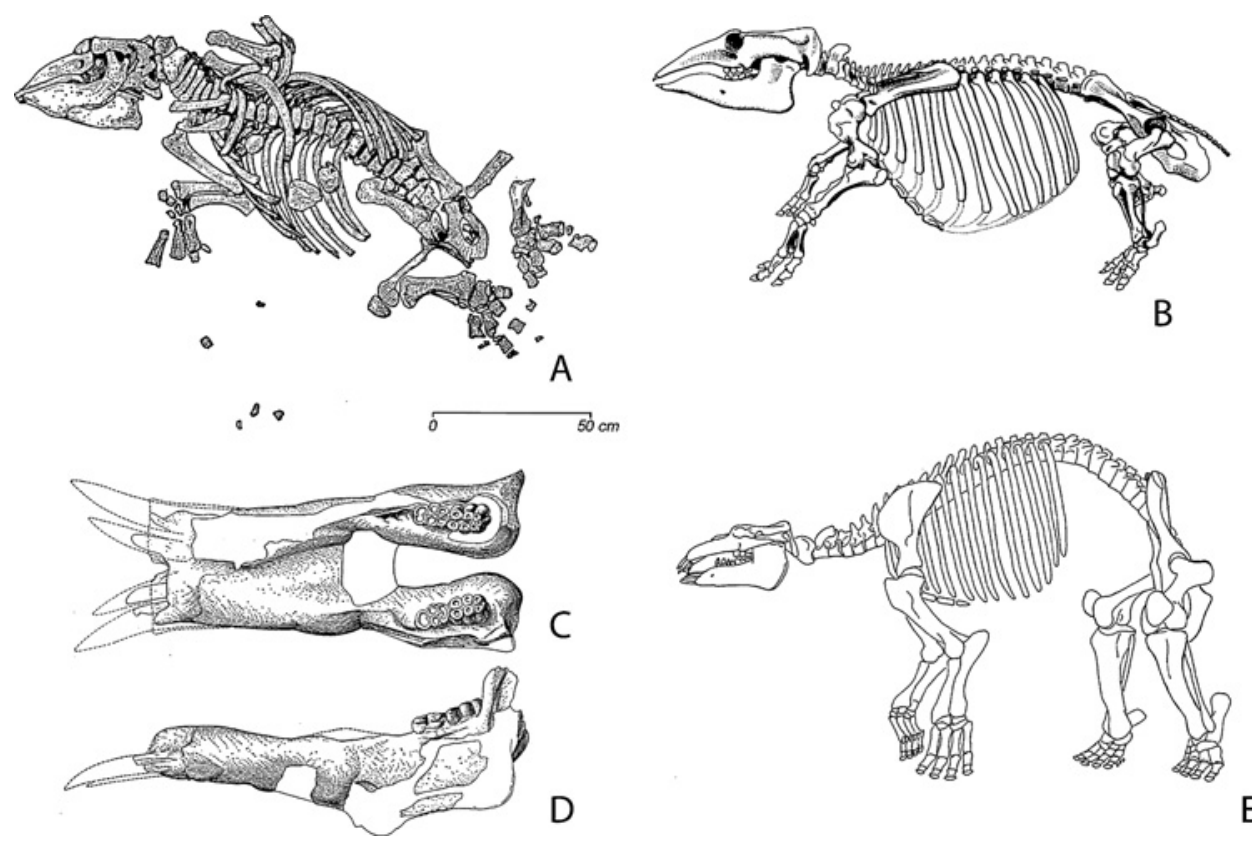

Fig. 1. Skeletal remains of Miocene Desmostylus hesperus and Paleoparadoxia tabatai. (A) Desmostylus hesperus: articulated skeleton of subadult Utanobori specimen (FSJ F7743) illustrated by Inuzuka (1984). Note presence of 13 thoracic and four lumbar vertebrae. (B) Desmostylus hesperus: reconstructed skeleton of mature Keton specimen (UHR 18466) analyzed here. Skeleton was described by Shikama (1966) and Inuzuka (1984; scale: humerus length ca. $41 \mathrm{~cm}$ ); reconstruction showing herpetiform posture is from Inuzuka (1984). (C-D) Desmostylus hesperus, partially reconstructed mandible in occlusal and lateral views (UCMP 32742) showing procumbent tusks and distinctive 'pillar-bundle' molars characteristic of the genus (reproduced from Reinhart, 1959; scale: dentary length as preserved ca. $54 \mathrm{~cm}$ ). (E) Paleoparadoxia tabatai, reconstructed skeleton of subadult Izumi specimen (UNSTM-P-5601) described by Shikama (1966; scale: humerus length ca. $40 \mathrm{~cm}$ ) and Domning (2002). Reconstruction is that of Domning (2002).

which Marsh (1888) highlighted in proposing the name Desmostylus (Gr., desma, bundle, and stylos, pillar). Marsh interpreted Desmostylus as a sirenian, but Desmostylus and its relatives are now generally placed in a distinct order Desmostylia. Six genera of desmostylians are commonly recognized: Behemotops (Paleoparadoxidae), and Ashoroa and Cornwallius (Desmostylidae) from the late Oligocene; and Paleoparadoxia (Paleoparadoxidae), and Desmostylus and Kronokotherium (Desmostylidae) from the early and middle Miocene (reviewed in Inuzuka et al., 1995; Inuzuka, 2000a).

Desmostylians are interpreted as semiaquatic because they are found exclusively in marine strata, supporting the idea that they were aquatic, while at the same time they retain large fore- and hind limbs suggestive of terrestrial locomotion. Retracted nares and raised orbits are additional cranial features characterizing semiaquatic mammals that are present in desmostylians. Stable isotopes of carbon, oxygen, and strontium in Desmostylus tooth enamel have ratios associated with aquatic vegetation (carbon) and life in an aquatic milieu (oxygen), but also fresh or brackish aquatic values (strontium; Clementz et al., 2003), reinforcing the idea that they were aquatic.

Some of the most interesting evolutionary transitions involve a change of adaptive zone, such as a change from life on land to life in water. Morphological compromises are 
required of semiaquatic animals that must move and function on or in both solid and liquid substrates. Each evolutionary transition from land to sea is an independent experiment, and such experiments rarely involve the same starting form or traverse the same environmental landscape of opportunities and constraints. Chance too dictates that the outcome is likely to be different in each instance. The questions addressed here concern the relative degree of aquatic adaptation in desmostylians, and the nature of this adaptation.

There are no living relatives of Desmostylia, and thus it is challenging to infer how they lived and moved. The most common approach to functional interpretation of a skeleton is to mount it bone by bone, joining all matching articular surfaces, and then to infer behavior based on the relative sizes of functional elements and their ranges of possible motion. This has been applied to Desmostylia with mixed success and conflicting results (Inuzuka, 1984; Repenning and Packard, 1990; Domning, 2002).

Here I take a different and quantitative approach to compare two pairs of alternative hypotheses proposed for Paleoparadoxia and extended, by implication, to Desmostylia in general. These concern, first, the relative degree of aquatic adaptation (hypothesis 1A versus $1 \mathrm{~B}$ ), and second, the relative importance of forelimbs and hind limbs in swimming (hypothesis $2 \mathrm{~A}$ versus $2 \mathrm{~B}$ ):

\section{Aquatic Versus Terrestrial}

(1A) Shikama (1966) wrote that "desmostylids were more skillful in swimming than in terrestrial locomotion" (Shikama, 1966, p. 147). This was reinforced by Repenning and Packard, who claimed that Paleoparadoxia was "as poorly adapted to terrestrial locomotion as are modern otarioid pinnipeds" (Repenning and Packard, 1990, p. 203).

(1B) Domning (2002) regarded Paleoparadoxia as "a slow, heavy, quadrupedal herbivore that often had to support much of its weight on its hindquarters when climbing over extremely uneven, rocky, slippery ground ... [It] is not necessary to look beyond the realm of purely terrestrial mammals to find detailed resemblances to the limbs of desmostylians. The latter, ..., might be thought of as 'sea sloths"' (Domning, 2002, pp. 107-108).

\section{Forelimb Versus Hind Limb Dominated Swimming}

(2A) Repenning and Packard (1990) wrote that "in swimming the posture of the hind limbs was most efficient and frog-like" in Paleoparadoxia (Repenning and Packard, 1990 , p. 203). The implication in general terms is that desmostylians were hindlimb dominated swimmers.

(2B) Domning (2002) considered that "locomotion in the water probably resembled that of polar bears, with alternate pectoral paddling as the principal means of propulsion and the hind limbs used for steering" (Domning, 2002, p. 99). The implication in general terms is that desmostylians were forelimb dominated swimmers.

Desmostylus is studied here rather than Paleoparadoxia because it is the only desmostylian known from a sufficiently complete skeleton. Desmostylus is relevant to both questions because it is considered to be the most specialized and probably most aquatic of all known Desmostylia (Inuzuka, 2000b). 


\section{SKELETON OF DESMOSTYLUS}

The only described desmostylian skeleton complete enough to analyze here is the Keton skeleton of Desmostylus hesperus (Hokkaido University, Sapporo, specimen UHR 18466). This was found by laborers in the timber trade in 1933, in the bed of the Keton River at Keton, near Poronaisk (Shisuka-machi) in central Sakhalin Island. Most of the specimen was collected in 1934, and it was first described by Nagao (1935) as the type of a new species, Desmostylus mirabilis (now considered a junior synonym of $D$. hesperus; Inuzuka, 2000a). The skeleton was first mounted for exhibition in 1936 (Nagao, 1941) and a revised reconstruction by Kamei remains on exhibit in the Hokkaido University Museum in Sapporo. Nagao's mount was taken apart to enable study of the original bones, but replicas remain on exhibit at the Osaka City National Science Museum and at the Ashoro Museum of Paleontology.

Shikama (1966) published the first full description of the Keton Desmostylus skeleton, including measurements of many elements. This description was augmented by Inuzuka (1984), who provided additional measurements of vertebral centra, and evidence from a new juvenile Desmostylus skeleton (Utanobori; Fig. 1A) that D. hesperus had a total of 13 thoracic vertebrae and four lumbar vertebrae.

Measurements analyzed here are listed with their source (Shikama, 1966; or Inuzuka, 1984) in Table I. Shikama provided measurements of forelimb bones, including lengths of the humerus (Shikama, 1966, p. 29), radius (p. 33), manual phalanx III-1 (p. 62), and manual phalanx III-2 (p. 68); and of hind limb bones, including the femur (p. 78), tibia (p. 82), metatarsal III (p. 100), pedal phalanx III-1 (p. 111), and pedal phalanx III-2 (p. 117). These were supplemented by Inuzuka, who provided measurements of centrum length in lumbar vertebrae L1-L3 (Inuzuka, 1984, p. 223), and the length of the scapula, humerus, radius, ilium, femur, and tibia (pp. 226-229).

The length of the thoracic column as a whole (T1-T13) is estimated to have been twice the length of the scapula, and these proportions match closely in all three skeletal mounts of the specimen (Inuzuka, 1984). The length of the lumbar series as a whole (L1-L4) includes measurements provided by Inuzuka (1984), with L4 estimated to have been the length of L3. The length of metacarpal III is estimated to have been twice that of metatarsal III (following Domning, 2002, p. 104). And finally, the length of the ilium reported by Inuzuka (1984) was supplemented by adding one-half the minimum diameter of the acetabulum.

\section{ANALYSIS}

Principal components analysis (PCA) of trunk and limb proportions in semiaquatic mammals has been described in detail by Gingerich (2003). This study makes use of the same reference set of 14 variables, all measurements of trunk and limb elements (listed in Table I), for 50 cases: living semiaquatic species belonging to nine orders of mammals (listed in Gingerich, 2003: Tables III and V). The same PCA analysis of the computed $14 \times 14$ correlation matrix for ln-transformed measurements is used here as well. The first principal axis, PC-I, explains $94.1 \%$ of the variance, PC-II explains 3.6\%, PC-III explains $0.7 \%$, and additional axes not considered here explain successively smaller proportions of the remaining variance. In a "shrew-to-walrus" comparison of skeletons like that considered here, size is a large proportion of the total variance, but smaller components of variance are important too to the extent that they reflect interpretable differences in skeletal proportions. 


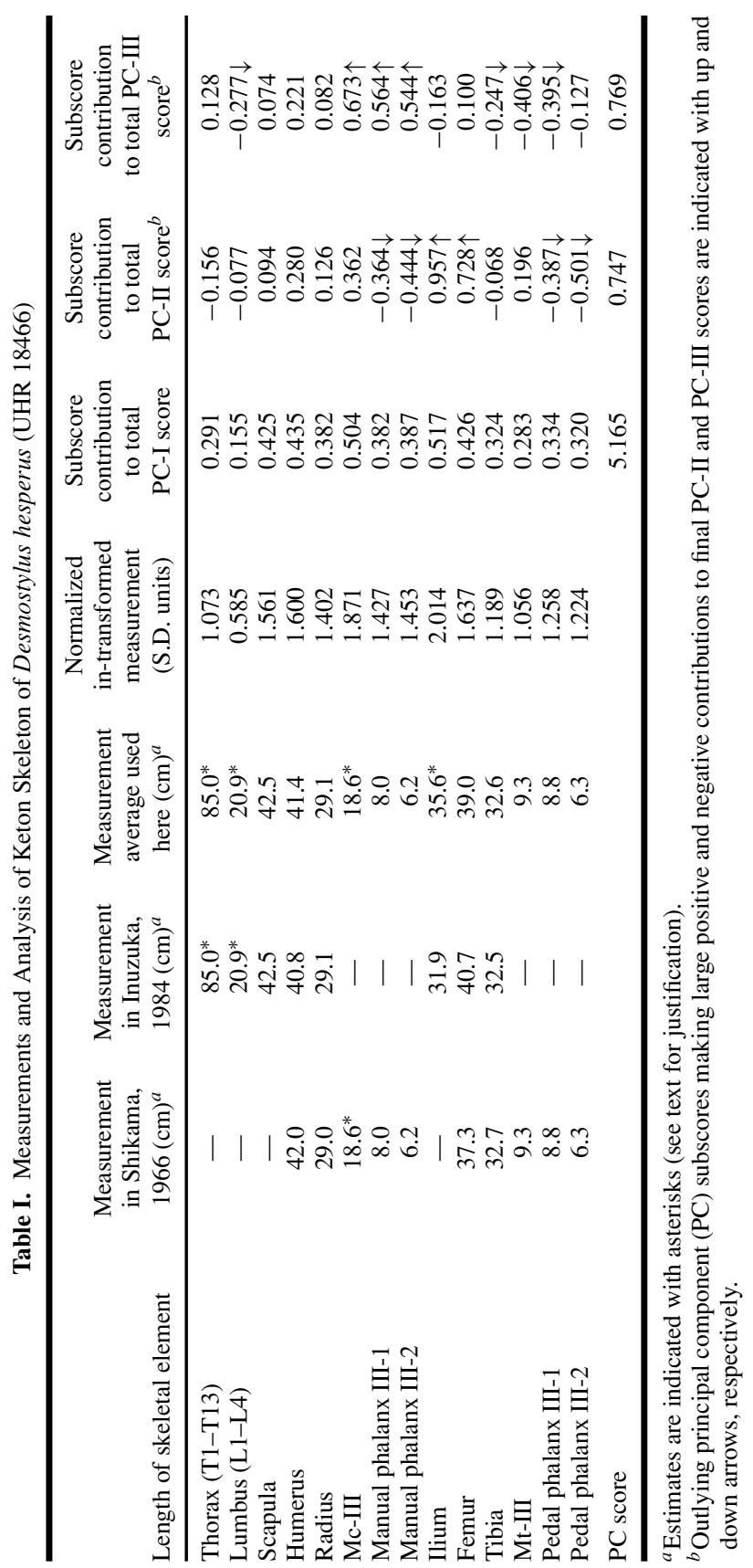


Desmostylus was not included as part of the PCA itself, but rather added as a supplemental taxon plotted in the three-dimensional space of body size versus degree of aquatic adaptation versus swimming mode reduced from the original 14-dimensional multivariate space. Adding Desmostylus requires normalizing the 14 skeletal measurements in Table I (as described in the caption to Table VI of Gingerich, 2003; utilizing mean and standard deviation values for each measurement provided in that table). Normalized measurements for Desmostylus, expressed in standard deviation units, are listed in Table I. Multiplication of the normalized measurements by the corresponding eigenvector coefficient for each principal component yields the contribution of each measurement to the final score on that principal component. Eigenvector coefficients for the set of 50 extant semiaquatic species are given in Gingerich (2003: Table VI), and the resulting subscores for each measurement of Desmostylus contributing to PC-I, PC-II, and PC-III scores are listed here in Table I. The total score for each PC axis in Table I is the corresponding coordinate for Desmostylus in the reduced three-dimensional coordinate system contrasting body size versus degree of aquatic adaptation versus swimming mode in semiaquatic mammals.

It goes without saying that PCA is a statistical approach to simplification of what is sometimes incomprehensible complexity. The relative positions of particular taxa on any one axis may be distorted slightly as a result. However, such compromises are usually more than justified by insight gained of broader patterns, which is certainly the case here.

Principal components analysis is no substitute for articulation followed by functional analysis of complete skeletons, but PCA can guide functional interpretation by showing efficiently how skeletal proportions of functional significance compare across a wide range of mammals.

\section{Principal Components Plots}

Principal components I and II are plotted against each other in Fig. 2, with Desmostylus hesperus added to the plot as an open diamond. PC-I on the abscissa corresponds to a size axis, separating water shrews like Neomys fodiens (Ne.fo. in Fig. 2) at the small end of the size spectrum, from mammals like the hippopotamus Hippopotamus amphibius and walrus Odobenus rosmarus (Hi.am. and Od.ro. in Fig. 2) at the large end of the spectrum (Gingerich, 2003). Desmostylus has a slightly higher PC-I score than any taxon included in the original analysis, which is consistent with it having been a large mammal similar in size to a hippopotamus or walrus.

PC-II on the ordinate in Fig. 2 corresponds to a terrestrial versus aquatic axis, separating tapirs like Tapirus indicus (Ta.in. in Fig. 2) at the terrestrial end of the semiaquatic spectrum, from mammals like the Ross seal Ommatophoca rossi, (Om.ro. in Fig. 2) at the aquatic end of the spectrum (Gingerich, 2003). Desmostylus has a PC-II score intermediate between those of the hippopotamus and the walrus, implying that it is more aquatic than the former and less aquatic than the latter.

Principal components II and III are plotted against each other in Fig. 3, with Desmostylus hesperus again added as an open diamond. Here PC-II is plotted on the ordinate to facilitate comparison with Fig. 2. The scale is expanded in Fig. 3 relative to that in Fig. 2, but PC-II is otherwise the same in both figures.

PC-III on the abscissa in Fig. 3 corresponds to a forelimb versus hind-limb dominated swimming axis, separating the duck-billed platypus Ornithorhynchus anatinus (Or.an. in 


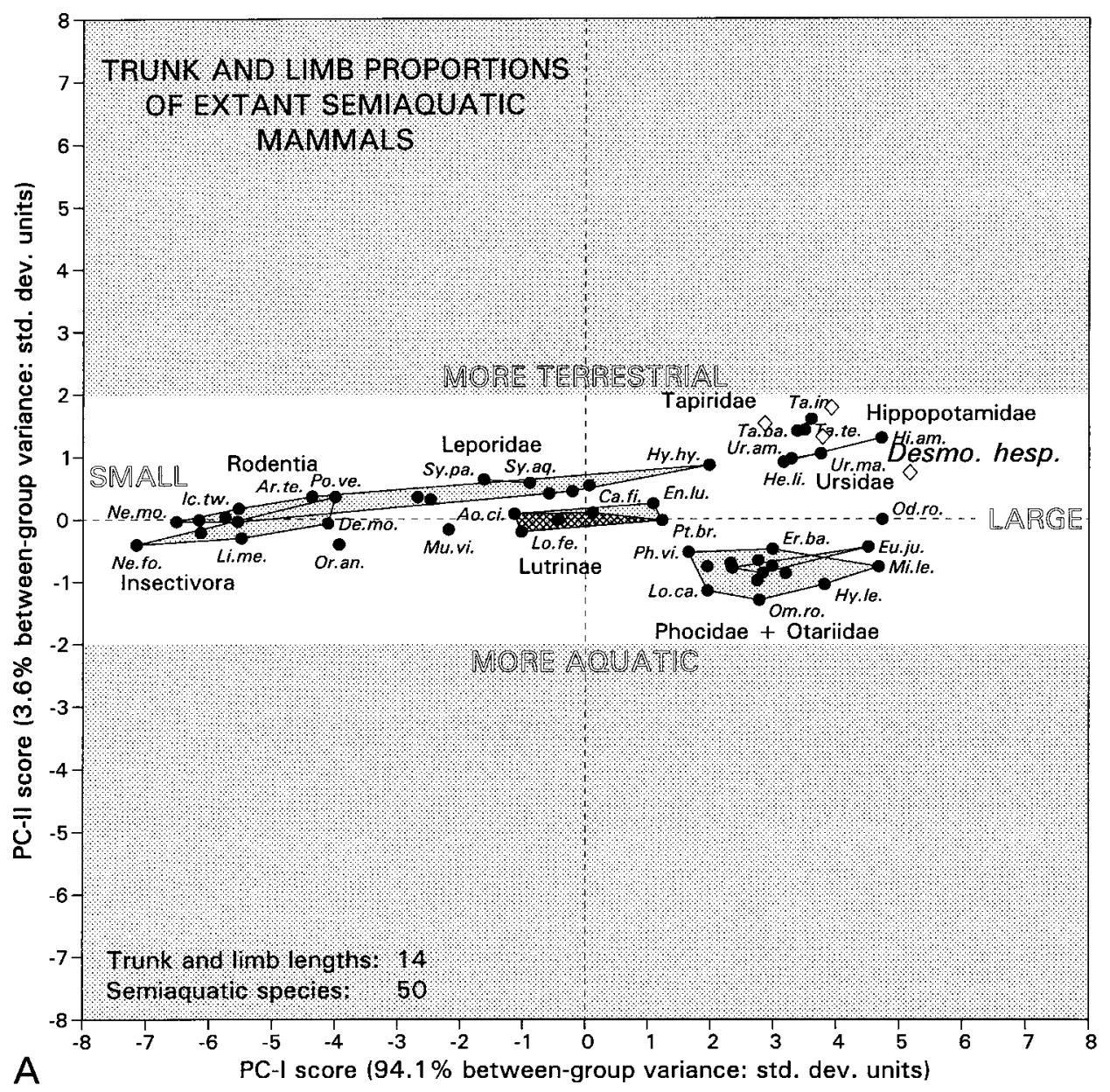

A

PC-I score ( $94.1 \%$ between-group variance: std. dev. units)

B
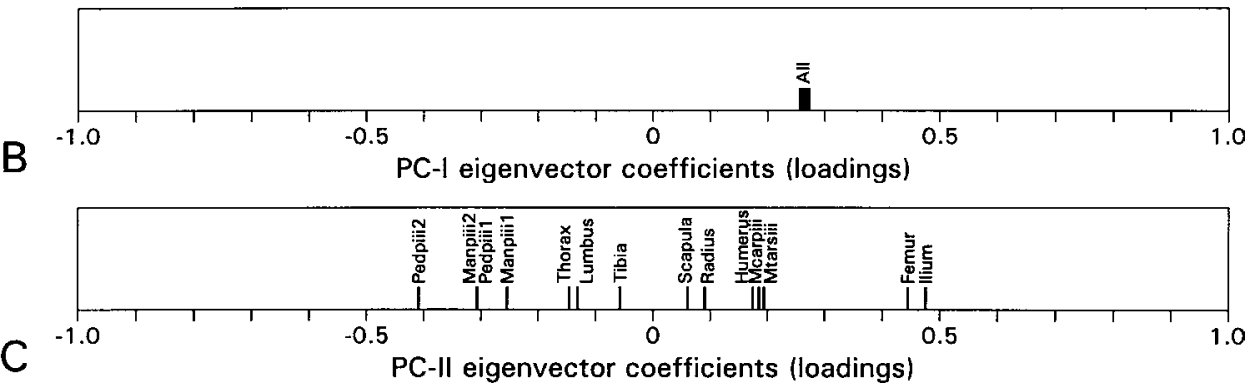

Fig. 2. Principal components analysis of extant semiaquatic mammals based on the correlation matrix for 14 variables and 50 cases. (A) PC-I (abscissa) vs. PC-II (ordinate). Note that Desmostylus hesperus (open diamond) falls at the large end of the size range on the size axis (PC-I), and between the polar bear Ursus maritimus (Ur.ma.) and walrus Odobenus rosmarus (Od.ro.) in terms of aquatic adaptation (PC-II). (B) Eigenvector coefficients or loadings on PC-I; note tight cluster of all trunk and limb lengths measured. (C) Eigenvector coefficients or loadings on PC-II; note contrast between a long femur and ilium with short manual and pedal phalanges characteristic of terresterial mammals, and a short femur and ilium with long manual and pedal phalanges characteristic of aquatic mammals. 


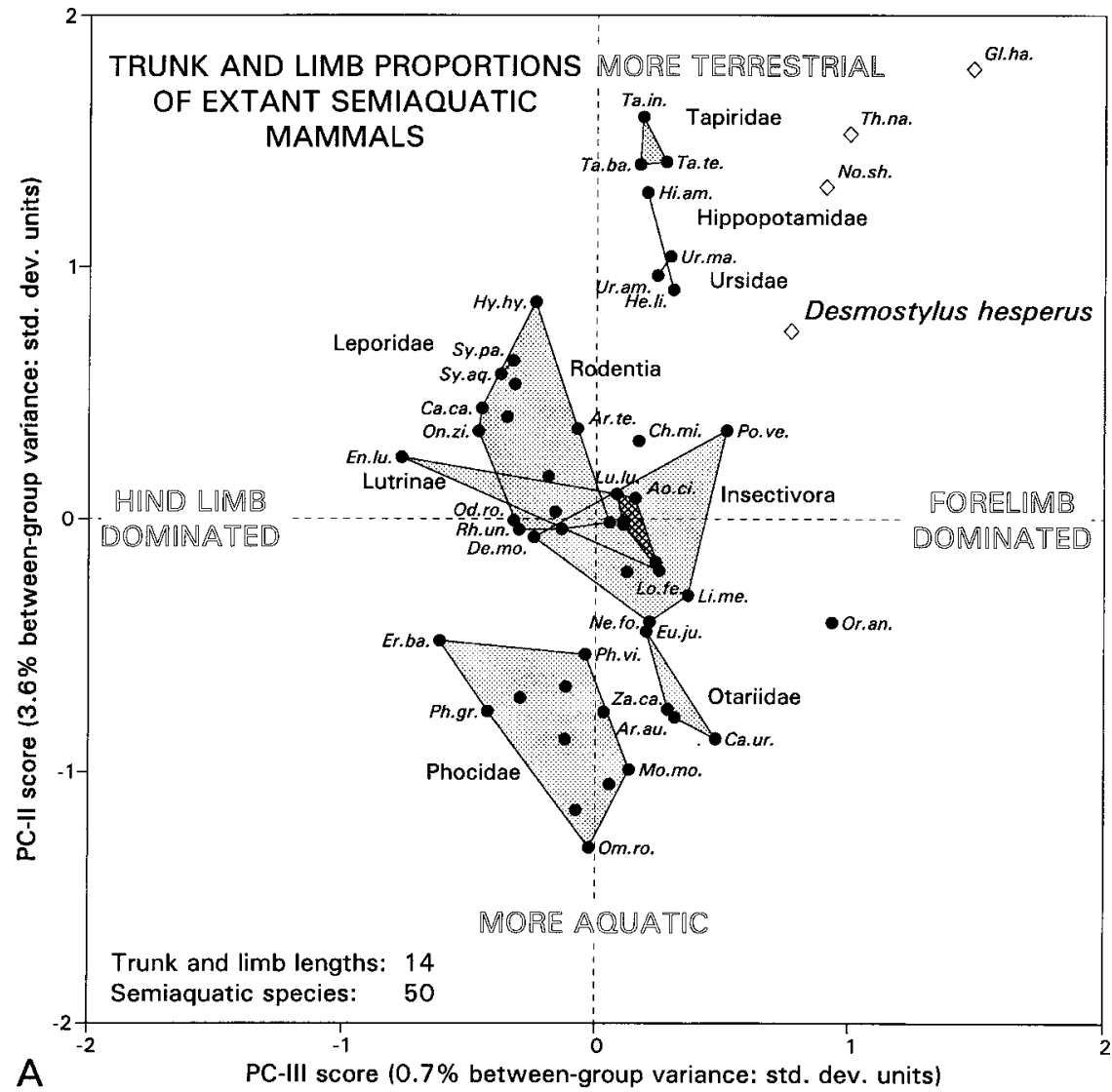

A

PC-III score $10.7 \%$ between-group variance: std. dev. units

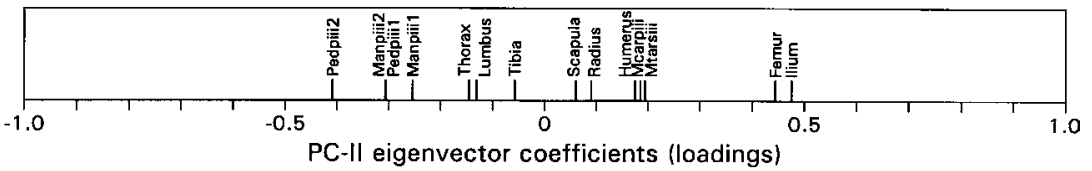

C

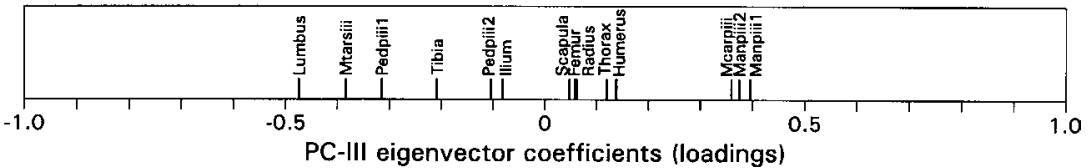

Fig. 3. Principal components analysis of extant semiaquatic mammals based on the correlation matrix for 14 variables and 50 cases. (A) PC-III (abscissa) vs. PC-II (ordinate). Note that Desmostylus hesperus (open diamond) falls between the polar bear Ursus maritimus (Ur.ma.) and walrus Odobenus rosmarus (Od.ro.) in terms of aquatic adaptation (PC-II), and well to the right of the polar bear in terms of forelimb domination. Desmostylus hesperus falls well below the sloths Nothrotheriops shastensis and Glossotherium harlani (open diamonds labeled No.sh. and My.ha., respectively), indicating that it is substantially more aquatic. (B) Eigenvector coefficients or loadings on PC-II; note contrast between a long femur and ilium with short manual and pedal phalanges characteristic of terrestrial mammals, and a short femur and ilium with long manual and pedal phalanges characteristic of aquatic mammals. (C) Eigenvector coefficients or loadings on PC-III; note contrast between long metacarpals and long manual phalanges with a short lumbus, short metatarsals, and short pedal phalanges characteristic of forelimb-dominated swimmers, and short metacarpals and short manual phalanges with a long lumbus, long metatarsals, and long pedal phalanges characteristic of hindlimb-dominated swimmers. 
Fig. 3) at the forelimb dominated end of the swimming spectrum, from mammals like the sea otter Enhydra lutris (En.lu. in Fig. 3) at the hind-limb dominated end of the spectrum. Desmostylus has a PC-III score intermediate between that of the more or less similarly aquatic polar bear Ursus maritimus (Ur.ma. in Fig. 3) and the duck-billed platypus Ornithorhynchus anatinus (Or.an. in Fig. 3).

\section{Principal Components Subscores}

The position of Desmostylus hesperus in the reduced three-dimensional semiaquatic space considered here depends on its scores or coordinates on each axis. As explained above, each score is the sum of a series of products of eigenvector coefficients (computed from measurements of the reference set of living semiaquatic mammals), and normalized measurements for the taxon of interest. The products themselves are subscores that tell us something about the contribution each measurement makes to the position of a taxon in multivariate space.

All of the subscores for PC-I in Table I are positive. There are differences among them, but these differences are not great. Ilium length and Mc-III length contribute more than expected, indicating that they are relatively large for a semiaquatic mammal, while lumbus length contributes conspicuously less than average, indicating that it is relatively small.

Subscores for PC-II in Table I exhibit stronger contrasts. The more important differences are indicated by arrows in the table. Here there is a distinct contrast between ilium and femur length on one hand, with subscores of +0.957 and +0.728 , respectively, and manual and pedal phalanx III-1 and phalanx III-2 lengths, with subscores ranging from -0.501 to -0.364 . Mammals with a long ilium and femur but short phalanges tend to be more terrestrial, and this is the strongest contrast pulling Desmostylus in this direction.

Subscores for PC-III with strong contrasts are again indicated by arrows in Table I. Here the strongest contrast is between Mc-III length and manual phalanx III-1 length, at +0.673 and +0.564 , respectively, versus Mt-III length and pedal phalanx III-1 length at -0.406 and -0.395 , respectively. Mammals with long metacarpals and manual phalanges but short metatarsals and pedal phalanges tend to be forelimb powered swimmers and this is the strongest contrast pulling Desmostylus in this direction.

\section{DISCUSSION}

The first pair of alternative hypotheses outlined above concerned how aquatic versus how terrestrial Desmostylus might have been. Shikama (1966) and Repenning and Packard (1990) indicated that desmostylians were more skillful in swimming than in terrestrial locomotion. Domning (2002) on the other hand regarded desmostylians as slow, heavy, quadrupedal herbivores and dubbed them "sea sloths." The position of Desmostylus hesperus on the spectrum of more terrestrial versus more aquatic mammals in Figs. 1 and 2, with a score on PC-II well above the median for semiaquatic mammals, indicates that desmostylians were more terrestrial than aquatic. Shikama (1966) and Repenning and Packard (1990) appear to have been wrong in claiming that desmostylians were more skillful in swimming than in terrestrial locomotion, and Domning appears to have been right in regarding desmostylians as more terrestrial than aquatic. 
The second pair of alternative hypotheses outlined above concerned whether desmostylians were hind-limb or forelimb dominated. Repenning and Packard (1990, p. 203) considered the hind limbs "most efficient and frog-like." Domning (2002, p. 99) on the other hand inferred that "locomotion in the water probably resembled that of polar bears," which are forelimb dominated paddlers. The position of Desmostylus hesperus on the spectrum of more hind-limb versus forelimb dominated mammals in Fig. 3, with a score on PC-III well above the median for semiaquatic mammals, indicates that desmostylians were clearly forelimb dominated swimmers, and their swimming is reasonably interpreted as having been bear-like. Repenning and Packard (1990) were probably wrong in considering desmostylians to have been efficient foot-powered swimmers, and Domning (2002) was probably right in comparing their swimming to that of bears.

Among species of similar size in the study set, the species most similar to Desmostylus is the polar bear. Projection of Desmostylus on PC-II shows it to have been more aquatically proportioned than a polar bear (because of its relatively short ilium and femur combined with relatively long metapodials and phalanges). Projection of Desmostylus on PC-III suggests that its aquatic locomotion was even more forelimb-dominated than that of a bear (because of its relatively long metacarpal III and corresponding proximal phalanx combined with a relatively short metatarsal III and corresponding proximal phalanx). Domning's idea that desmostylians were "sea sloths" because of their sloth-like proportions cannot really be evaluated without comparing sloths explicitly, and three were added for this purpose in Figs. 2 and 3. These are the ground sloths Nothrotheriops shastensis and Glossotherium harlani, with measurements taken from Stock (1925), and the marine sloth Thalassocnus natans de Muizon and McDonald (1995), and with measurements provided by the authors. All three sloths were plotted following the procedure outlined above for Desmostylus hesperus, and each is represented by an open diamond in Figs. 2 and 3. The diamonds are labeled No.sh., Gl.ha., and Th. na., respectively, in Fig. 3. Sloths are forelimb dominated relative to most mammals, somewhat like Desmostylus, but Desmostylus hesperus was clearly more aquatic in its overall trunk and limb proportions than sloths are. Whether this was true of Paleoparadoxia, the principal subject of Domning's investigation, remains to be investigated when a more complete set of skeletal measurements is published. Domning (2002) shows Paleoparadoxia tabatai as having had 15 thoracic and eight lumbar vertebrae, which means that it cannot have been identical to Desmostylus hesperus.

Desmostylians are properly classified in their own extinct order, but among living mammals Desmostylus appears to be most similarly proportioned to bears, and bears provide an appropriate baseline for imagining what desmostylians were like in life. Thus rather than calling desmostylians "sea sloths," desmostylians (Desmostylus at least) might more appropriately be dubbed "sea bears" (such an association with the polar bear is not altogether unwarranted, though obviously desmostylians were not carnivorous nor really bears). A bear-like model appears to be appropriate for Desmostylus, based on trunk and limb proportions, but this remains to be tested for Paleoparadoxia.

Finally, we can speculate a little about the lifestyle of Desmostylus. Clementz et al. (2003) interpreted stable isotope ratios to indicate that Desmostylus spent much of its time in water, foraging on aquatic vegetation in estuarine or even freshwater environments. The large size of adult desmostylians probably insulated them from most predation. In addition, a coastal marine distribution would have provided protection too, enabling escape from terrestrial predators by going into the water, and escape from aquatic predators by moving 
out of the water onto land. Infants and young desmostylians would have been vulnerable in both environments of course, it is easy to imagine that birthing and early development took place in refuges on selected offshore islands. It seems doubtful that desmostylians living in an open coastal environment were able to be as solitary and cryptic as bears often are living in forests on land today, and the social organization of desmostylians may have provided some safety from predators if they were living and foraging in groups.

\section{ACKNOWLEDGMENTS}

It is a pleasure to recall the many times and places I have encountered William A. Clemens over the years, none more surprising than a chance meeting at Down House a few years ago, when for a moment I thought the Master had come home! I was working on semiaquatic mammals at the time, the backbone of the application presented here. Desmostylian teeth remind me, as they would anyone who has seen them, of the formidable clusters of outstanding students Bill Clemens has trained over the years. I thank two of these outstanding students, David Polly and Zhexi Luo, for inviting me to Berkeley when Bill Clemens retired, and for the invitation to contribute here. William J. Sanders got me started on this study when he gave a guest lecture on tethytheres in my course on fossil mammals. Free to think, as he presented the material, I wondered how desmostylians might compare to other semiaquatic mammals. Most of what I know of desmostylians I learned, directly or indirectly, from Norihisa Inuzuka and Daryl Domning. I thank Norihisa Inuzuka, Daryl Domning, David Polly, and an anonymous reviewer for thorough readings improving the manuscript. Christian de Muizon and H. Gregory McDonald generously provided measurements of Thalassocnus.

\section{LITERATURE CITED}

Clementz, M. T., Hoppe, K. A., and Koch, P. L. (2003). A paleoecological paradox: The habitat and dietary preferences of the extinct tethythere Desmostylus, inferred from stable isotope analysis. Paleobiology 29: 506-519.

Domning, D. P. (2002). The terrestrial posture of desmostylians. In: Cenozoic Mammals of Land and Sea: Tributes to the Career of Clayon E. Ray, R. J. Emry, ed. Smithson. Contr. Paleobiology 93: 99-111.

Gingerich, P. D. (2003). Land-to-sea transition of early whales: Evolution of Eocene Archaeoceti (Cetacea) in relation to skeletal proportions and locomotion of living semiaquatic mammals. Paleobiol. 29: 429-454.

Inuzuka, N. (1984). Skeletal restoration of the Desmostylians: Herpetiform Mammals. Mem. Fac. Sci. Kyoto Univ. Ser. Biol. 9: 157-253.

Inuzuka, N. (1996). Body size and mass estimates of desmostylians (Mammalia). J. Geol. Soc. Japan 102: 816-819.

Inuzuka, N. (2000a). Primitive late Oligocene desmostylians from Japan and phylogeny of the Desmostylia. Bull. Ashoro Mus. Paleontol. 1: 91-123.

Inuzuka, N. (2000b). Preliminary report on the evolution of aquatic adaptation in desmostylians (Mammalia, Tethytheria). Oryctos 3: 71-77.

Inuzuka, N. (2005). The Stanford skeleton of Paleoparadoxia (Mammalia: Desmostylia). Bull. Ashoro Mus. Paleontol. 3: 3-10.

Inuzuka, N., Domning, D. P., and Ray, C. E. (1995). Summary of taxa and morphological adaptations of the Desmostylia. In: Evolution and Biogeography of Fossil Marine Vertebrates in the Pacific Realm, L. G. Barnes, N. Inuzuka, and Y. Hasegawa, eds., Volume 3, pp. 522-537, Blackwell Science, Carlton, The Island Arc.

Marsh, O. C. (1888). Notice of a new fossil sirenian from California. Am. J. Sci. 35: 94-96.

Nagao, T. (1935). Desmostylus mirabilis nov. from Sakhalin. J. Geol. Soc. Japan 42: 822-824.

Nagao, T. (1941). On the skeleton of Desmostylus (in Japanese). In: Jubilee Publication to Commemorate Prof. H. Yabe's 60th Birthday, pp. 43-52. 
Muizon, C. D., and McDonald, H. G. (1995). An aquatic sloth from the Pliocene of Peru. Nature 375: 224-227. Reinhart, R. H. (1959). A review of the Sirenia and Desmostylia. Univ. Calif. Publ. Geol. Sci. 36: 1-146.

Repenning, C. A., and Packard, E. L. (1990). Locomotion of a desmostylian and evidence of ancient shark predation. In: Evolutionary Paleobiology of Behavior and Coevolution, A. J. Boucot, ed., pp. 199-203, Elsevier, Amsterdam.

Shikama, T. (1966). Postcranial skeletons of Japanese Desmostylia. Palaeontol. Soc. Japan Spec. Pap. 12: 1-202.

Stock, C. (1925). Cenozoic gravigrade edentates of western North America, with special reference to the Pleistocene Megalonychinae and Mylodontidae of Rancho La Brea. Carneg. Inst. Washing. Publ. 331: 1-206. 